\title{
MORPHOMETRIC CHARACTERISTICS OF RED CHITTAGONG CATTLE IN A NUCLEUS HERD
}

\author{
M. Hadiuzzaman, A. K. F. H. Bhuiyan*, M. S. A. Bhuiyan and M. A. Habib
}

\begin{abstract}
The present study was undertaken measuring a total of 78 animals of Red Chittagong Cattle (RCC) of different ages and sexes maintained under a USDA funded RCC project at Bangladesh agricultural University (BAU) Dairy Farm, Mymensingh. The experiment was conducted to estimate different body measurements of RCC at different age groups. A total of 12 different age groups at 6 months interval were considered for estimation. The age groups were 1-6, 7-12, 13-18, 19-24, 25-30, 31-36, 37-42, 43-48, 49-54, 55-60, 61-66 and 66+ months. Different body measurements were wither height, hip height, body length, chest diameter, chest width, hip width, thurl width and rump length. As expected, it was found that all measurements significantly increased $(\mathrm{P}<0.01)$ with the advancement of age. All the estimates reached in maximum level at the highest age class (66+ months) in this study except chest width and rump length (61-66 and 4348 months class, respectively). It also observed that all the estimates were gradually increased with age, but the rate of increment varied for different measurements for different age groups. The results also revealed to conclude no definite ages at which the estimates reached a maximum level due to lack of animals of more than 66 months of age to composite further age groups.
\end{abstract}

Key words: Morphometric characteristics, RCC, Nucleus herd

\section{Introduction}

Most of the indigenous cattle in Bangladesh are of indicus type and are kept by the $80 \%$ of the rural people of the country. Depending upon the climate, soil type and availability of fodder, different types or variety of cattle genetic resources are available in different parts of the country like Non descript Deshi, Red Chittagong, Pabna, North Bengal Grey, Madaripur, Hilly and Munshigong (Bhuiyan et al., 2005). But Red Chittagong Cattle (RCC) is one of the promising varieties of cattle genetic resource of Bangladesh. They attribute good qualities like good adaptability to traditional husbandry practices, subsistence on poor quality feeds and fodders, regularity in breeding and better resistance capabilities to withstand environmental stress and tropical diseases (Bhuiyan et al., 2005). The bullocks of this breed are active, useful for light ploughing and carting and are remarkable for their speed and stamina. RCC possess some distinguishable features in their appearance and body characteristics. They are noble and handsome looking animals. Their power of draught and

*Corresponding author: Prof. Dr. A. K. Fazlul Haque Bhuiyan, E-mail: bhuiyanbau@gmail.com Department of Animal Breeding \& Genetics, Bangladesh Agricultural University, Mymensingh, Bangladesh

(Received: April 28, 2010) 
Bang. J. Anim. Sci. 2010, 39(1\&2)

spirit of endurance are appreciable. The head of the RCC are somewhat erect with moderately long face. Well carried on short and stout neck rising over the withers into a medium and noticeable hump which is short in female and large in male while erect inclined vertically for both. Horns are medium and stumpy, tapering to a blunt point. Ears are moderately long and alert and slightly dropping. They possess medium and flesh dewlap which are fairly depth and broad between the fore arms. Clean leg but not so massive, well apart firmly and squarely set under the body. They are humped, especially male are big humped up to 6-8".

The morphometric measurement is conducted for the assessment of carcass quantity as well as to characterize breeds of animals. Live weight is an important trait in cattle farming. Weighing is not always feasible and therefore live weight is often estimated from easily accessible morphometric data (Coopman et al., 2009). Conformation is an indicator of carcass composition (Laville et al., 1995). Laville et al. (1996) studied the relationships among morphological traits and bovine carcass composition traits in order to select carcass measurements to derive equations for predicting muscle weight, percentage of muscle and muscle to bone ratio. The study on morphometric measurement is very scanty for the indigenous cattle of Bangladesh; however Namikawa et al. (1984); Habib et al. (2003); AlAmin (2004); Hossain et al. (2006); Bhuiyan et al. (2007) and Bag et al. (2010) studied some morphometric characters for indigenous cattle of Bangladesh. Considering the aforesaid identification, the present research work was aimed to determine the morphometric characteristics of RCC reared in a nucleus herd at Bangladesh Agricultural University (BAU).

\section{Materials and Methods}

The study was conducted under a USDA funded Red Chittagong Cattle Project at BAU, Mymensingh. The morphological measurements were taken from 78 animals including different ages and sexes (Table 1) and were recorded for this study.

The feeding and management systems at the nucleus herd were almost similar because stall feeding was practiced throughout the year. Straw treated with urea and /molasses was the basal bulk diet supplied ad lib where green fodder were supplied very limited amount. Concentrate feeds such as oil cake, wheat bran, rice polish, corn, salt and vitamin-mineral premix mixture were also supplied @600 g/d/lactating cows, 500 g/d/pregnant cow, 400 $\mathrm{g} / \mathrm{d} / \mathrm{dry}$ and heifer and $250 \mathrm{~g} / \mathrm{d} / \mathrm{calf}$. Animals were dewormed and vaccinated regularly according to prevailing diseases and parasites.

The present study covered different morphological characters which included wither height, hip height, body length, chest diameter, chest width, hip width, thurl width and rump length of animals of different ages and sexes at the nucleus herd. The description of those measurements is given in Table 2 . 
Table 1. Distribution of data set for measuring morphometric characters

\begin{tabular}{|c|c|c|c|}
\hline Age class (month) & Male & Female & Total \\
\hline $1-6$ & 4 & 6 & 10 \\
$7-12$ & 3 & 4 & 7 \\
$13-18$ & 3 & 6 & 9 \\
$19-24$ & 1 & 3 & 4 \\
$25-30$ & 1 & 3 & 4 \\
$31-36$ & 0 & 5 & 5 \\
$37-42$ & 0 & 4 & 4 \\
$43-48$ & 0 & 4 & 4 \\
$49-54$ & 0 & 5 & 5 \\
$55-60$ & 0 & 8 & 8 \\
$61-66$ & 0 & 7 & 7 \\
$66+$ & 0 & 11 & 11 \\
\hline Total & 12 & 66 & 78 \\
\hline
\end{tabular}

Table 2. Description of different morphometric measurements of RCC

\begin{tabular}{|l|l|}
\hline \multicolumn{1}{|c|}{ Trait } & \multicolumn{1}{c|}{ Description } \\
\hline Wither height & Vertical distance between the fetlock and the point of wither. \\
Hip height & Vertical distance between the fetlock and the point of hip bone. \\
Body length & Distance between points of shoulder to pin bone. \\
Chest diameter & It was the diameter surrounding the heart girth of the animal. \\
Chest width & Chest width was measured as the broadest portion of the chest. \\
Hip width & Distance between two hip bones of the animal. \\
Thurl width & Distance between pin bone to hip bone. \\
Rump length & Distance between parts of base of tail to hip bone \\
\hline
\end{tabular}

The animals were of different ages and there were both parents (male and female) and progeny groups. Therefore, there were sufficient unbalances in the data material. In other words, the numbers of observations were different from class to class. So, the statistical design of the study was non- orthogonal factorial in nature. For analyzing the data materials both simple descriptive statistics as well as Completely Randomized Design (CRD) with unequal sample sizes were used. For comparing means of the different sub-classes, least significant difference (LSD) test was applied using SPSS 11.5 computer program.

The mathematical equation followed for this analysis was as follows:

$$
\mathrm{Y}_{\mathrm{ijK}}=\mu+\mathrm{S}_{\mathrm{i}}+\mathrm{A}_{\mathrm{j}}+\mathrm{e}_{\mathrm{ijK}}
$$


Bang. J. Anim. Sci. 2010, 39(1\&2)

Where $\mathrm{Y}_{\mathrm{ijK}}=$ morphometric measurement of $\mathrm{i}^{\text {th }}$ sex of $\mathrm{j}^{\text {th }}$ age class of $\mathrm{K}^{\mathrm{th}}$ animal.

$\mu=$ Population mean

$\mathrm{S}_{\mathrm{i}}=$ Fixed effect of $\mathrm{i}^{\text {th }}$ sex $(1=$ male and $2=$ female $)$

$A_{j}=$ Fixed effect of $j^{\text {th }}$ age class $(j=1,2,3, \ldots \ldots \ldots \ldots, 12)$

$\mathrm{e}_{\mathrm{ijk}}=$ Random residual error

\section{Results and Discussion}

Least squares means along with their standard errors of different mophometric measurements of the said traits of RCC at different ages were estimated (Table 3) and discussed below.

Table 3. Morphometric measurements of RCC for different age classes with level of significance

\begin{tabular}{|c|c|c|c|c|c|c|c|c|}
\hline \multirow{2}{*}{$\begin{array}{c}\text { Age } \\
\text { class } \\
\text { (Month) }\end{array}$} & \multicolumn{8}{|c|}{$\begin{array}{c}\text { Measurement }(\mathrm{cm})^{1} \\
(\text { Mean } \pm \text { SE) }\end{array}$} \\
\hline & WH & HH & BL & CD & CW & HW & TW & RL \\
\hline $1-6$ & $72.29 \pm .31$ & $73.76 \pm 0.37$ & $68.70 \pm 0.42$ & $81.49 \pm 0.36$ & $18.15 \pm 0.35$ & $15.66 \pm 0.36$ & $21.56 \pm 0.45$ & $20.65 \pm 0.43$ \\
\hline $7-12$ & $81.48 \pm 0.40$ & $81.57 \pm 0.42$ & $73.66 \pm 0.44$ & $96.54 \pm 0.20$ & $18.59 \pm 0.40$ & $17.55 \pm 0.40$ & $23.60 \pm 0.44$ & $21.62 \pm 0.38$ \\
\hline $13-18$ & $86.49 \pm 0.40$ & $89.64 \pm 0.25$ & $78.90 \pm 0.32$ & $124.91 \pm 0.28$ & $19.17 \pm 0.25$ & $20.25 \pm 0.45$ & $23.99 \pm 0.30$ & $24.07 \pm 0.38$ \\
\hline $19-24$ & $92.47 \pm 0.32$ & $92.60 \pm 0.44$ & $89.38 \pm 0.30$ & $125.23 \pm 0.28$ & $20.61 \pm 0.25$ & $22.36 \pm 0.43$ & $25.06 \pm 0.51$ & $26.62 \pm 0.31$ \\
\hline $25-30$ & $94.89 \pm 0.34$ & $96.48 \pm 0.49$ & $92.99 \pm 0.34$ & $126.29 \pm 0.38$ & $23.65 \pm 0.48$ & $24.93 \pm 0.45$ & $26.44 \pm 0.44$ & $27.85 \pm 0.44$ \\
\hline $31-36$ & $98.65 \pm 0.31$ & $98.62 \pm 0.31$ & $97.25 \pm 0.28$ & $126.48 \pm 0.33$ & $25.23 \pm 0.35$ & $26.31 \pm 0.41$ & $27.33 \pm 0.37$ & $31.07 \pm 0.33$ \\
\hline $37-42$ & $103.61 \pm 0.48$ & $99.98 \pm 0.71$ & $98.67 \pm 0.37$ & $127.35 \pm 0.29$ & $25.86 \pm 0.29$ & $27.07 \pm 0.33$ & $29.60 \pm 0.53$ & $32.50 \pm 0.43$ \\
\hline $43-48$ & $107.41 \pm 0.19$ & $103.66 \pm 0.47$ & $100.08 \pm 0.72$ & $128.91 \pm 0.42$ & $26.23 \pm 0.33$ & $26.57 \pm 0.38$ & $30.29 \pm 0.49$ & $37.07 \pm 0.51$ \\
\hline $49-54$ & $108.43 \pm 0.23$ & $104.70 \pm 0.70$ & $106.06 \pm 0.57$ & $132.49 \pm 0.43$ & $26.26 \pm 0.32$ & $29.58 \pm 0.60$ & $33.30 \pm 0.40$ & $34.19 \pm 0.60$ \\
\hline $55-60$ & $108.57 \pm 0.29$ & $107.23 \pm 0.46$ & $108.26 \pm 0.31$ & $135.51 \pm 0.20$ & $28.01 \pm 0.58$ & $28.81 \pm 0.51$ & $35.71 \pm 0.22$ & $36.47 \pm 0.69$ \\
\hline $61-66$ & $111.05 \pm 0.26$ & $108.36 \pm 0.25$ & $108.48 \pm 0.24$ & $136.13 \pm 0.26$ & $29.20 \pm 0.61$ & $29.34 \pm 0.42$ & $36.60 \pm 0.55$ & $36.94 \pm 0.47$ \\
\hline $66+$ & $112.21 \pm 0.56$ & $109.82 \pm 0.49$ & $110.60 \pm 0.45$ & $137.22 \pm 0.48$ & $28.82 \pm 0.45$ & $30.69 \pm 0.50$ & $37.95 \pm 0.48$ & $33.26 \pm 0.49$ \\
\hline $\begin{array}{l}\text { Level of } \\
\text { Sig. }\end{array}$ & $* *$ & $* *$ & ** & $* *$ & $* *$ & ** & $* *$ & $* *$ \\
\hline
\end{tabular}

${ }^{1}$ WH-wither height; HH-hip height; BL-body length; CD-chest diameter; CW-chest width; HW-hip width; TW-thurl width; RL-rump length; ** = Significance at $\mathrm{P}<0.01$

\section{Wither height}

The result of wither height found in this study for age group of 43-48 months was closely agreed by Bag et al., (2010); Hossain et al. (2006) and Habib et al. (2003) in their studies for body height (105.86 $\pm 5.25,105.94 \pm 2.17$ and $107.71 \pm 0.93 \mathrm{~cm}$, respectively) in adult female of RCC. Bhuiyan et al. (2005) measured height at wither of adult RCC female and found $107.71 \mathrm{~cm}$ which also strongly supported the results of this study. The results of the present study were found to be lower than the results of Bhuiyan et al. (2007) for Pabna cows and Gaur et al. (2003) for Indian Ponwar cows who reported that the average wither height 
of adult cows were $118.21 \pm 3.25$ and $109.0 \pm 0.4 \mathrm{~cm}$, respectively. Al-Amin (2004) however reported lower $(93.91 \pm 1.13 \mathrm{~cm}$ ) estimate of wither height for North Bengal Grey cows. In this study, the wither height at 24 months of age was strongly supported by the result of Namikawa et al. (1984) who reported $100.32 \pm 2.79 \mathrm{~cm}$ for Bangladeshi native cattle. In another study by Singh et al., (2002) reported wither height for Indian Deoni cattle as 86.45 $\pm 1.87,98.51 \pm 3.46,107.94 \pm 2.32,112.50 \pm 2.23,122.06 \pm 2.39$ and $122.22 \pm 1.23 \mathrm{~cm}$, respectively for the age groups of 4-6, 10-12, 13-18, 19-24, $>24$ and adult cows which were greater values than that of this study. Fig. 1 showed a gradual increasing trend $(\mathrm{P}<0.01)$ of measurements with progressing age.

\section{Hip height}

The hip heights of RCC at different ages are depicted in Table 3. Namikawa et al. (1994) measured hip height of Bangladeshi native cattle at more than two years old and found $103.37 \pm 6.47 \mathrm{~cm}$ which agreed strongly by the result of this study. In contrast, Vinoo et al. (2003) reported hip height of Ongole cattle of India as $147.47 \mathrm{~cm}$ at 60 months of age. Statistical analyses of these measurements also revealed that the hip height of RCC was significantly increased $(\mathrm{P}<0.01)$ with advancement of age (Fig. 1).

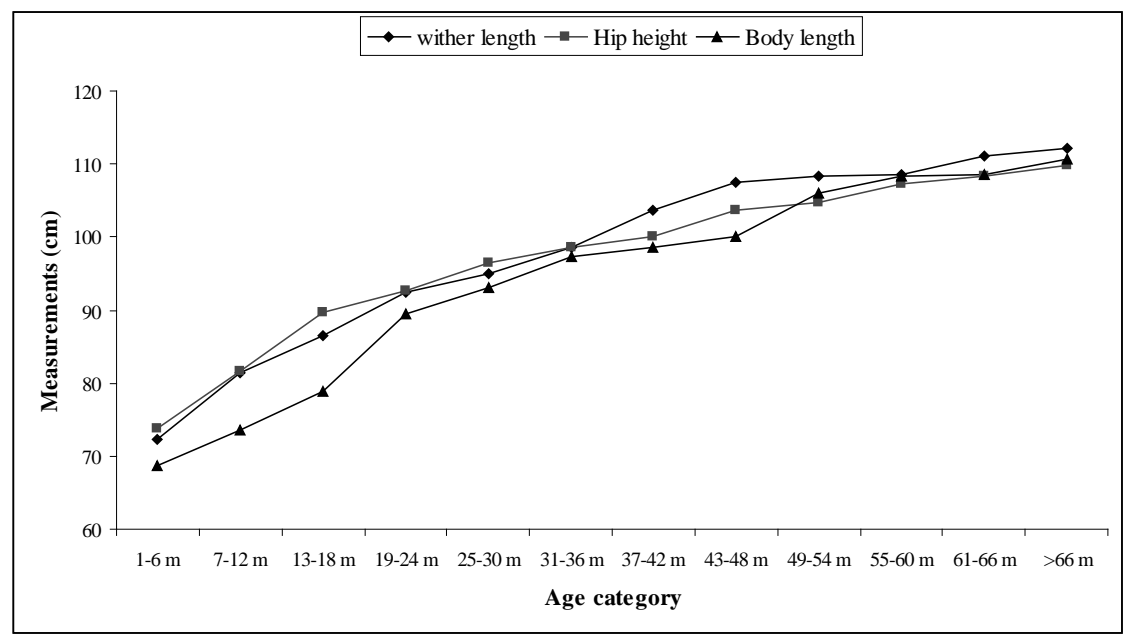

Fig. 1. Trends of body measurements according to age

\section{Body length}

The average body length of this study at 60 months of age was lower than the findings of Vnioo et al. (2003) who reported $144.11 \mathrm{~cm}$ for Ongole cattle at that age. The result was consistent for the age of 54 months by the results found by Al-Amin (2004) for North Bengal Grey cows $(105.16 \pm 1.21 \mathrm{~cm})$, Hossain et al. (2006) for RCC $(107.13 \pm 2.17 \mathrm{~cm})$ and Bag et al. (2010) for RCC $(106.89 \pm 3.58 \mathrm{~cm})$. The result of this study were not in accordance with the results found by Habib et al. (2003) for RCC $(114.38 \pm 1.56 \mathrm{~cm})$ and Bhuiyan et al. (2007) for Pabna cows $(164.39 \pm 2.36 \mathrm{~cm})$. Singh et al. (2002) in their published literature reported body length for Indian Deoni cattle as $78.45 \pm 1.86$, $93.30 \pm 2.34,101.56 \pm 1.50$, 
Bang. J. Anim. Sci. 2010, 39(1\&2)

$103.52 \pm 2.59,116.43 \pm 2.06$ and $120.11 \pm 2.16 \mathrm{~cm}$, respectively for the age groups of 4-6, $10-12,13-18,19-24,>24$ and adult cows which were much higher values than the corresponding values found by this study. A significant $(\mathrm{P}<0.01)$ increasing trend with progressing age was found in this study for body length of RCC (Fig. 1).

\section{Chest diameter}

Bag et al., (2010), Hossain et al. (2006) and Habib et al. (2003) reported heart girth of adult RCC female cows to be $136.88 \pm 6.18,136.90 \pm 2.22$ and $139.85 \pm 1.63 \mathrm{~cm}$, respectively which were closely in agreement by the result found in this study for the age of $66+$ months (Table 3). Al-Amin (2004) reported $126.95 \pm 1.53 \mathrm{~cm}$ heart girth for North Bengal Grey cattle which was smaller than this study; however Bhuiyan et al. (2007) found relatively larger heart girth $(147.56 \pm 1.70 \mathrm{~cm})$ for Pabna cows in their studies. Namikawa et al. (1984) measured chest diameter of Bangladeshi native cattle at more than two years old to be 50.79 $\pm 2.45 \mathrm{~cm}$ which was much smaller than this study at this age. In another study by Singh et al., (2002) reported chest girth for Indian Deoni cattle as $94.56 \pm 3.85,114.53 \pm 3.31,124.97$ $\pm 2.73,129.73 \pm 5.31,144.83 \pm 2.81$ and $151.82 \pm 1.92 \mathrm{~cm}$, respectively for the age groups of $4-6,10-12,13-18,19-24,>24$ and adult cows which partially agreed in particular ages by this study.

The analysis of variance showed a significant $(\mathrm{P}<0.01)$ increasing trend of chest diameter with advancement of age (Fig. 2).

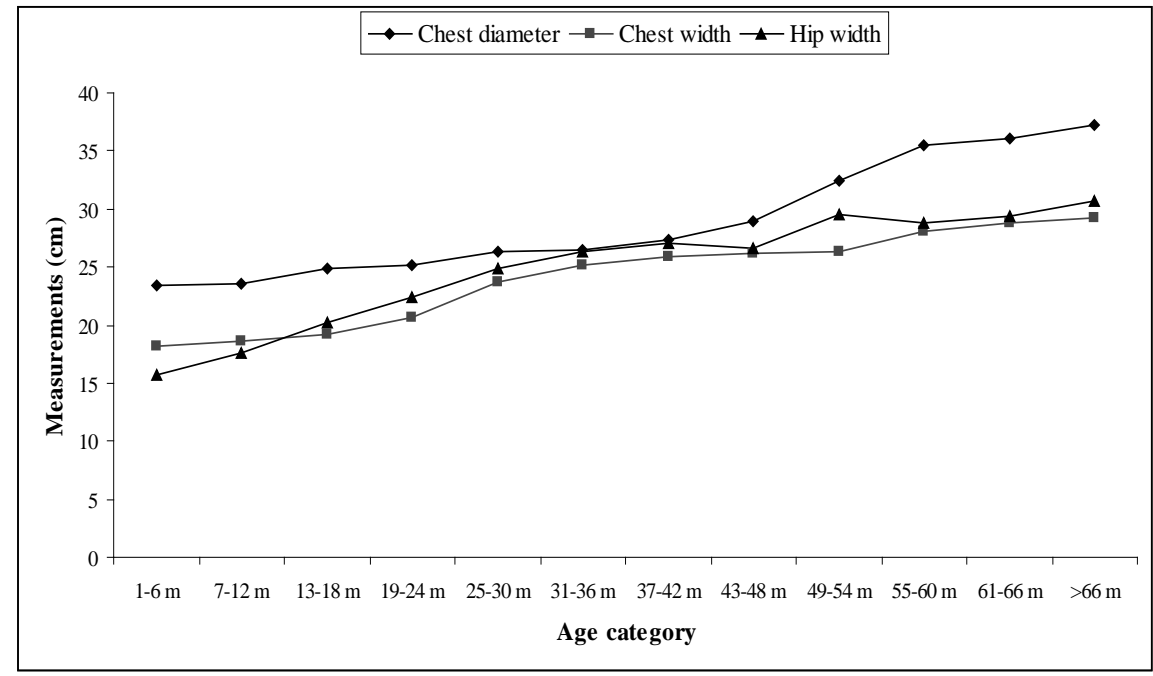

Fig. 2. Trends of body measurements according to age

\section{Chest width}

The chest widths at different ages are given in Table 3. Namikawa et al. (1984) measured chest width of Bangladeshi cattle and found to be $23.67 \pm 3.07 \mathrm{~cm}$ at more than 2 years of age which strictly agreed by this study. Fig. 2 tended to increase $(\mathrm{P}<0.01)$ the chest width gradually and reached peak up to 61-66 months of age and declined slightly after that age. 


\section{Hip width}

The hip widths of RCC at different ages are depicted in Table 3. Namikawa et al. (1984) reported hip width of Bangladeshi cattle to be $33.21 \pm 2.05 \mathrm{~cm}$ at more than 2 years age which was not in agreement with this study. Statistical analysis of these measurements revealed that the hip width of RCC was significantly $(\mathrm{P}<0.01)$ increased with advancement of age (Fig. 2).

\section{Thurl width}

The measurements of thurl width of the said age classes are given in Table 3. Namikawa et al. (1984) found thrul width of Bangladeshi native cattle to be $30.07 \pm 2.06 \mathrm{~cm}$ at more than 2 years age which agreed with the measurement of 43-48 months age group cows found in this study. Statistical analysis of these measurements showed significant $(\mathrm{P}<0.01)$ increase with advancement of age (Fig. 3).

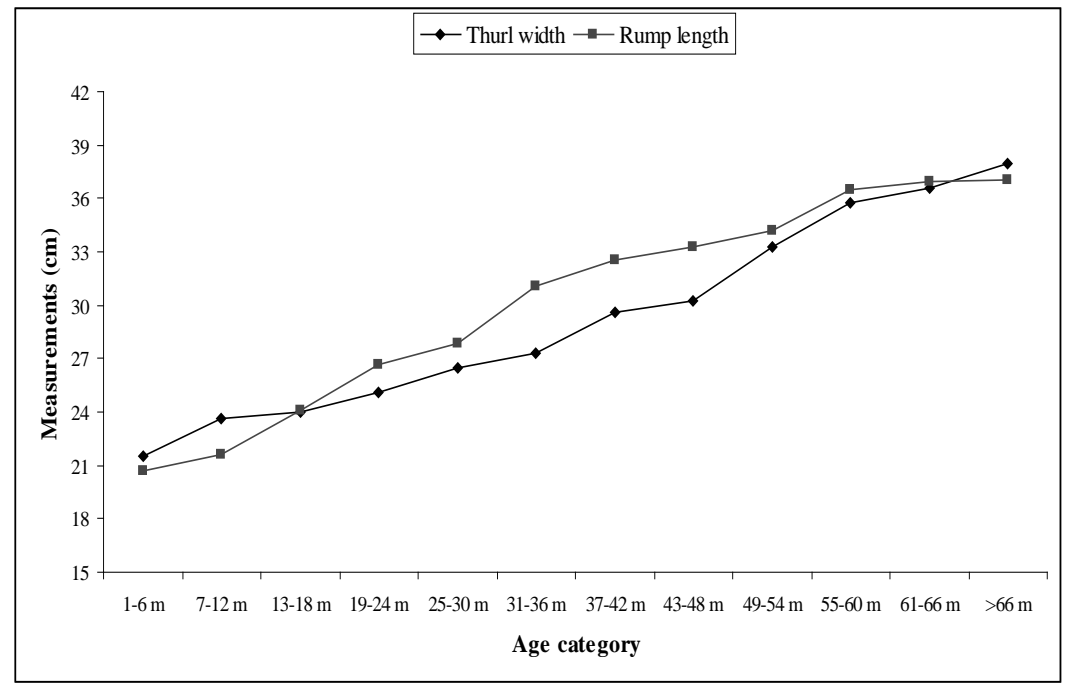

Fig. 3. Trends of body measurements according to age

\section{Rump length}

The rump lengths of RCC found from the animals of different ages are shown in Table 3. Namikawa et al. (1984) measured rump length of Bangladeshi native cattle at more than two years old and reported it to be $29.26 \pm 6.12 \mathrm{~cm}$ which was closely in agreement with this study for the measurement of age group 25-30 months. Rump length increased significantly $(\mathrm{P}<0.01)$ with progressing age (Fig. 3 ).

\section{Conclusion}

From the results and discussion above, it was clear that all morphological measurements of RCC significantly increased $(\mathrm{P}<0.01)$ with the advancement of age. The growth of all 
Bang. J. Anim. Sci. 2010, 39(1\&2)

measurements, studied were linear up to final ages studied except chest width and rump length. However, the growth of chest width and rump length increased linearly up to 66 months of age and decreased thereafter. Although morphometric measurements in adult RCC compared to other indigenous cattle of Bangladesh and India were somewhat alike but variations existed might be due to differences of genetic make up of growth traits of different breeds or types and different feeding and management systems the animals are pertained to.

\section{Literature Cited}

Al-Amin, M. 2004. Characterization of North Bengal Grey Cattle in Bangladesh. MS thesis, Department of Animal Breeding and Genetics, Bangladesh Agricultural University, Mymensingh.

Bag, M. A. S., Mannan, M. A., Khan, M. S. R., Parvez, M. M. and Ullah, S. M. 2010. Morphometric characterization and present status of Red Chittagong Cattle (RCC) in Chittagong district in Bangladesh. Int. J. BioRes., 1(2): 11-14.

Bhuiyan, A. K. F. H., Shahjalal, M., Islam, M. N., Rahman, A. K. M. A., Keown, J. F. and Van Vleck, L. D. 2005. Characterization conservation and improvement of Red Chittagong Cattle of Bangladesh. Bangladesh Agricultural University Research System (BAURES) Prog., 13-21.

Bhuiyan, A. K. F. H., Hossain, M. M. and Deb, G. K. 2007. Indigenous cattle genetic resources of Bangladesh and a way forward to their development. Bangladesh J. Prog. Sci. \& Tech., 5(1): 105-112.

Coopman, F., Smet, S. D., Laevens, H., Zeveren, A. V. and Duchateau, L. 2009. Live weight assessment based on easily accessible morphometric characteristics in the double-muscled Belgian Blue beef breed. Livest. Sci., 125(2): 318-322.

Gaur, G. K. Avtar, S., Singh, P. K. and Pundir, R. K. 2003. Morphometric characteristics and present status of Ponwar Cattle breed in India. Anim. Genet. Res. Info., 34:17-25.

Habib, M. A., Bhuiyan, A. K. F. H., Bhuiyan, M. S. A. and Khan, A. A. 2003. Performance of Red Chittagong Cattle in Bangladesh Agricultural University Dairy Farm. Ban. J. An. Sc., 32(1-2): 101-108.

Laville, E., Astruc, T., Martin, V. and Bousset, J. 1995. Estimation of the muscle to bone ratio of the bovine pelvic limb using a morphometric method. Meat Sci., 41(3): 345-355.

Laville, E., Martin, V. and Bastien, O. 1996. Prediction of composition traits of young Charolais bull carcasses using a morphometric method. Meat Sci., 44(1-2): 93-104.

Namikawa, T. and Tsubota, Y. 1984. Coat Color Variations, Body Conformation, Blood Groups and Blood Protein Polymorphisms in the Local Cattle Populations in Bangladesh, Genetic Studies on Breed differentiation of the Native Domestic Animals in Bangladesh. Tokyo University of Agriculture, Tokyo, Japan, pp. 11-24.

Singh, G., Gaur, G. K., Nivsarkar, A. E., Patil, G. R. and Mitkari, K. R. 2002. Deoni cattle breed of India. A study on population dynamics and morphometric characteristics. Anim. Genet. Res. Info., 32: 35-43.

Vinoo, R. and Rao, K. B. 2003. Morphometry and performance of Ongole cattle in breeding community. Indian Vet. J., 80 (8): 749-751. 